\title{
LANTERN: a randomized study of QVAI49 versus salmeterol/fluticasone combination in patients with COPD
}

This article was published in the following Dove Press journal: International Journal of COPD

5 June 2015

Number of times this article has been viewed

\section{Nanshan Zhong' \\ Changzheng Wang ${ }^{2}$ \\ Xiangdong Zhou ${ }^{3}$ \\ Nuofu Zhang' \\ Michael Humphries ${ }^{4}$ \\ Linda Wang ${ }^{4}$ \\ Chau Thach ${ }^{5}$ \\ Francesco Patalano 6 \\ Donald Banerji ${ }^{5}$ \\ On behalf of the LANTERN Investigators}

'State Key Laboratory of Respiratory Diseases, First Affiliated Hospital, Guangzhou Medical University, Guangzhou, Guangdong, ${ }^{2}$ Institute of Respiratory Disease, Xin Qiao Hospital, ${ }^{3}$ Department of Respiratory Medicine, Southwest Hospital, Third Military Medical University, Chongqing City, Chongqing, ${ }^{4}$ Beijing Novartis Pharma Co. Ltd., Shanghai, People's Republic of China; ${ }^{5}$ Novartis Pharmaceuticals Corporation, East Hanover, NJ, USA; ${ }^{6}$ Novartis Pharma AG, Basel, Switzerland
Correspondence: Nanshan Zhong State Key Laboratory of Respiratory Diseases, First Affiliated Hospital, Guangzhou Medical University, 151 Yangjiang Road, Guangzhou 510120, Guangdong, People's Republic of China Email nanshan@vip.163.com
Background: The current Global initiative for chronic Obstructive Lung Disease (GOLD) treatment strategy recommends the use of one or more bronchodilators according to the patient's airflow limitation, their history of exacerbations, and symptoms. The LANTERN study evaluated the effect of the long-acting $\beta_{2}$-agonist (LABA)/long-acting muscarinic antagonist (LAMA) dual bronchodilator, QVA149 (indacaterol/glycopyrronium), as compared with the LABA/inhaled corticosteroid, salmeterol/fluticasone (SFC), in patients with moderate-to-severe COPD with a history of $\leq 1$ exacerbation in the previous year.

Methods: In this double-blind, double-dummy, parallel-group study, 744 patients with moderate-to-severe COPD with a history of $\leq 1$ exacerbations in the previous year were randomized (1:1) to QVA149 110/50 $\mu \mathrm{g}$ once daily or SFC 50/500 $\mu \mathrm{g}$ twice daily for 26 weeks. The primary endpoint was noninferiority of QVA149 versus SFC for trough forced expiratory volume in 1 second $\left(\mathrm{FEV}_{1}\right)$ at week 26.

Results: Overall, 676 patients completed the study. The primary objective of noninferiority between QVA149 and SFC in trough FEV $_{1}$ at week 26 was met. QVA149 demonstrated statistically significant superiority to SFC for trough $\mathrm{FEV}_{1}$ (treatment difference $[\Delta]=75 \mathrm{~mL}$; $P<0.001)$. QVA149 demonstrated a statistically significant improvement in standardized area under the curve (AUC) from 0 hours to 4 hours for $\mathrm{FEV}_{1}\left(\mathrm{FEV}_{1} \mathrm{AUC}_{0-4 \mathrm{~h}}\right)$ at week 26 versus SFC $(\Delta=122 \mathrm{~mL} ; P<0.001)$. QVA149 and SFC had similar improvements in transition dyspnea index focal score, St George Respiratory Questionnaire total score, and rescue medication use. However, QVA149 significantly reduced the rate of moderate or severe exacerbations by $31 \%(P=0.048)$ over SFC. Overall, the incidence of adverse events was comparable between QVA149 (40.1\%) and SFC (47.4\%). The incidence of pneumonia was threefold lower with QVA149 (0.8\%) versus SFC (2.7\%).

Conclusion: These findings support the use of the LABA/LAMA, QVA149 as an alternative treatment, over $\mathrm{LABA}$ /inhaled corticosteroid, in the management of moderate-tosevere COPD patients (GOLD B and GOLD D) with a history of $\leq 1$ exacerbation in the previous year.

Keywords: COPD, long-acting $\beta_{2}$-agonists, long-acting muscarinic antagonist, clinical trial

\section{Introduction}

COPD is characterized by chronic airflow obstruction that interferes with normal breathing and is not fully reversible. The airflow limitation is usually progressive and associated with an abnormal inflammatory response of the lung to noxious particles or gases. ${ }^{1}$ COPD and, more specifically, the frequent and recurrent exacerbations experienced by patients with COPD, can result in significant health care costs, as well as causing high morbidity and mortality among this group. ${ }^{2-4}$ 
The Global Initiative for Chronic Obstructive Lung Disease (GOLD) strategy document recommends the use of one or more bronchodilators based on a patient's airflow limitation, his or her history of exacerbations, and symptoms. ${ }^{5}$ The goals of inhaled therapies are to improve dyspnea, quality of life, prevent disease progression, prevent exacerbations, and reduce mortality. ${ }^{5}$ Inhaled bronchodilator therapy consists of short-acting bronchodilators, long-acting $\beta 2$-adrenergic receptor agonists (LABA) and long-acting muscarinic receptor antagonists (LAMA). Inhaled corticosteroids (ICS), combined with LABAs, are recommended specifically in subgroups of COPD patients who are at an increased risk of exacerbations, as these patients are most likely to benefit from ICS therapy. ${ }^{6-8}$ Despite these recommendations, ICS and fixed-dose combinations containing an ICS are often prescribed earlier in the course of the disease to more moderate COPD patients. ${ }^{9,10}$ LABAs and LAMAs target complementary pathways leading to bronchodilation ${ }^{11}$ and, to date, numerous studies have confirmed significantly superior improvements in bronchodilation, symptoms, and quality of life with LABA/LAMA combinations when compared with the respective monotherapies alone. ${ }^{12-17}$

QVA149 is a fixed-dose combination of two longacting bronchodilators, indacaterol (QAB149, LABA) and glycopyrronium (NVA237, LAMA), for the once daily maintenance treatment of COPD. The ILLUMINATE study $^{18}$ demonstrated that QVA149 provided superior bronchodilation compared with LABA/ICS (salmeterol/ fluticasone $[\mathrm{SFC}]$ ) in patients with moderate-to-severe COPD without a history of exacerbations in the previous year. Furthermore, in the post hoc analysis of the ILLUMINATE study, ${ }^{19}$ QVA149 showed comparable results in terms of frequency and time to first exacerbation in patients without exacerbation in the previous year, as compared with SFC.
In this study (LANTERN), the efficacy and safety of QVA149 was compared with that of SFC in predominantly Chinese patients with moderate-to-severe COPD with a history of $\leq 1$ exacerbation in the previous year. Some of the results of this study have been previously reported in the form of an abstract. ${ }^{20}$

\section{Methods}

\section{Study design}

LANTERN was a 26-week, multicenter, randomized, double-blind, double-dummy, parallel-group study (Figure 1). The first patient was enrolled on November 8, 2012, and the last patient completed the study on February 28, 2014. After assessing the eligibility during a 14-day run-in period, patients were randomized (1:1) to receive either QVA149 $110 / 50 \mu \mathrm{g}$ once daily delivered via the Breezhaler ${ }^{\circledR}$ device (Novartis Pharma AG, Basel, Switzerland) or SFC 50/500 $\mu \mathrm{g}$ twice daily delivered via the Accuhaler ${ }^{\circledR}$ device (GlaxoSmithKline plc, London, UK) and matching placebos. More details are provided in the online Supplementary materials. The patients were treated in the morning (between 8 am and 11 am for both of the devices) and evening (approximately 12 hours after the morning dose; Accuhaler ${ }^{\circledR}$ device only).

\section{Patients}

This study enrolled male and female patients aged $\geq 40$ years with moderate-to-severe COPD (stage II and III, as defined in the GOLD 2010 criteria $^{21}$ ). All patients had a modified Medical Research Council (mMRC) grade $\geq 2$ at screening. Patients were excluded from this study if they had experienced more than one documented COPD exacerbation that required treatment with antibiotics and/or oral corticosteroids and/or hospitalization in the year before the screening visit or during the run-in period. Detailed inclusion and exclusion criteria, as well as the medication

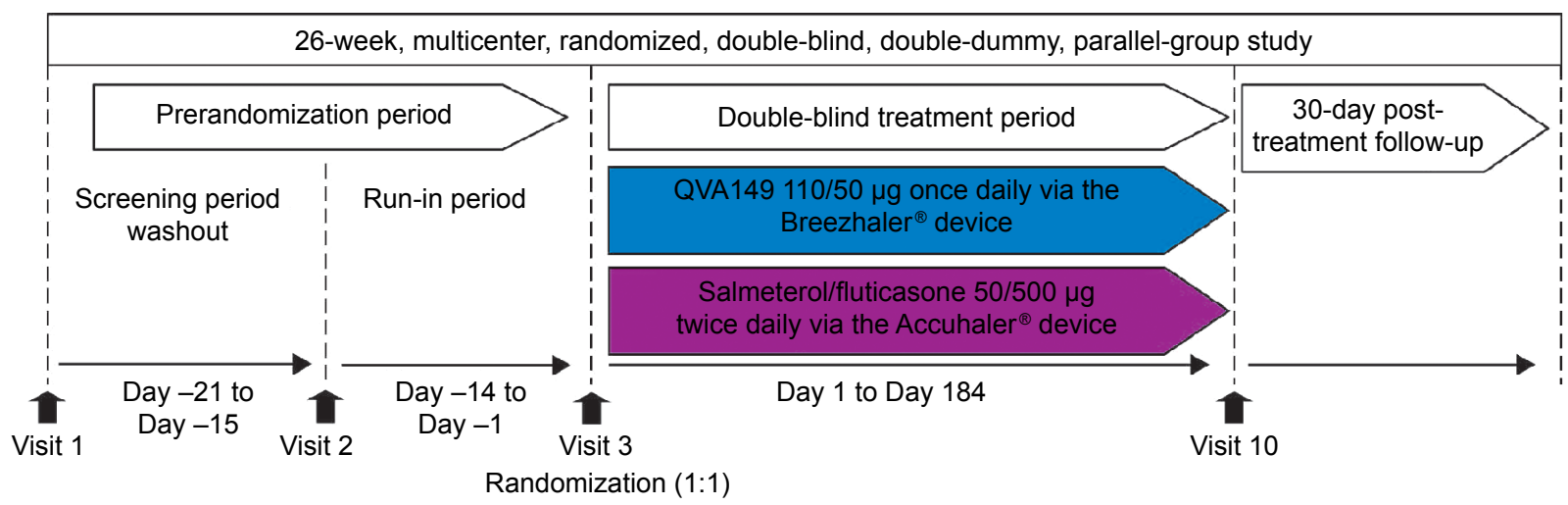

Figure I The LANTERN study design. 
allowed during the trial, are included in Tables $\mathrm{S} 1$ and $\underline{\mathrm{S}}$. All participants provided written informed consent, and the study was approved by institutional review boards and ethics committees at participating centers, and was conducted in accordance with the Declaration of Helsinki and Good Clinical Practice guidelines.

\section{Analysis}

Assessment and outcome measures

Spirometry measurements were recorded at all clinic visits (day 1 and at weeks 6, 12, 18, and 26), using centralized spirometry. A subset of patients had more frequent postdose spirometric measurements. More details and definitions of spirometry measurements are provided in the online Supplementary materials.

The primary objective was to demonstrate the noninferiority of QVA149 to SFC in terms of postdose trough forced expiratory volume in 1 second $\left(\mathrm{FEV}_{1}\right)$ at week 26 . The noninferiority margin was defined to be $-60 \mathrm{~mL}$, as per previous findings ${ }^{22}$ If noninferiority of QVA149 versus SFC was met, then QVA149 would be tested for superiority and controlled by the prespecified hierarchical procedure.

The key secondary objective was to determine the superiority of QVA149 to SFC in terms of the standardized area under the curve (AUC) from 0 hours to 4 hours postdose for $\mathrm{FEV}_{1}\left(\mathrm{FEV}_{1} \mathrm{AUC}_{0-4 \mathrm{~h}}\right)$ following 26 weeks of treatment.

Other secondary endpoints included: peak $\mathrm{FEV}_{1}$ and forced vital capacity (FVC); trough FVC; Transitional Dyspnea Index (TDI) focal score; and St George's Respiratory Questionnaire (SGRQ) total score at weeks 12 and 26. At all sites, patients used an electronic diary (e-diary) to capture the use of rescue medication, exacerbations, and other symptoms experienced during the study. Exploratory objectives included the assessment of health-related quality of life using the COPD assessment test (CAT) score at weeks 12 and 26 and COPD exacerbations that occurred over 26 weeks. The definition of exacerbations and safety assessments are provided in the online Supplementary materials.

\section{Statistical methods}

A sample size of 736 patients (QVA149, 368; and SFC, 368) was planned to be randomized and this number was adjusted for $25 \%$ dropouts until week 26 and those with major protocol deviations. The estimate for the standard deviation for trough $\mathrm{FEV}_{1}$ at week 26 was $210 \mathrm{~mL}$. For trough $\mathrm{FEV}_{1}$, it was assumed that the estimated treatment difference between QVA149 and SFC was $0 \mathrm{~mL}$ and the noninferiority margin was assumed to be $-60 \mathrm{~mL}$. This noninferiority margin was based on the treatment difference between $\mathrm{SFC}$ and placebo of $160 \mathrm{~mL}$ with a $95 \%$ confidence interval (CI) of 120-200 mL, as summarized in a Cochrane review. ${ }^{22} \mathrm{~A}$ reasonable approach to establish the noninferiority margin is to take onehalf of the lower bound of the CI, which is $-60 \mathrm{~mL}$. Using these assumptions, a sample size of 276 evaluable patients in each treatment group gave $91 \%$ power for the testing of noninferiority (2.5\% significance level, one-sided).

For key secondary variables, a sample size of 736 patients with 368 randomized to either the QVA149 or SFC treatment arms had at least $90 \%$ power to detect at least a $60 \mathrm{~mL}$ treatment difference in standardized $\mathrm{FEV}_{1} \mathrm{AUC}_{0-4 \mathrm{~h}}$ at week 26 between QVA149 and SFC using a two-sided test with a $5 \%$ significance level.

SAS version 9.3 was used to perform all the statistical analyses. The full analysis set (FAS) included all randomized patients who received at least one dose of the study drug. The per protocol set included all patients in the FAS without any major protocol deviations (study drug compliance $<80 \%$ or $>120 \%$, inclusion or exclusion criteria violation, etc). The safety population included all patients who received at least one dose of the study drug, regardless of whether the patient was randomized.

The primary endpoint, mean trough $\mathrm{FEV}_{1}$ after 26 weeks (imputed with the last observation carried forward), was analyzed using a mixed model. The model included treatment, smoking status (current/ex-smoker), COPD exacerbation history (yes/no), baseline ICS use (yes/no), and region as fixed effects; baseline $\mathrm{FEV}_{1}$ measurement and $\mathrm{FEV}_{1}$ reversibility as covariates; and center nested within region as a random effect. The estimated adjusted treatment difference for QVA149 to SFC was displayed along with the associated two-sided $95 \%$ CI. The objective of noninferiority was achieved if the lower bound of the $95 \%$ CI of the estimated treatment difference was greater than $-60 \mathrm{~mL}$ for the per protocol set. Superiority testing for QVA149 compared with SFC on the trough $\mathrm{FEV}_{1}$ was performed on the FAS after the primary objective was met in a hierarchical procedure to protect the overall type 1 error at 0.05 . There was no multiplicity adjustment on other secondary analyses.

Unless stated otherwise, secondary endpoints were evaluated using the same mixed model as in the primary endpoint on the FAS, but the respective baseline values replaced FEV as a covariate.

Moderate or severe COPD exacerbation was analyzed as an exacerbation rate by a negative binomial model, and time to first exacerbation by a Kaplan-Meier curve and Cox proportional hazard model. The negative binomial model and Cox 
proportional hazard model included treatment, baseline ICS use (yes/no), baseline total symptom score, baseline COPD exacerbation history (the number of COPD exacerbations in the year prior to screening), $\mathrm{FEV}_{1}$ reversibility components, smoking history (current/ex-smoker), and region.

All safety endpoints were summarized by treatment for the safety set. Further information on statistics and data analysis is provided in the online Supplementary materials.

\section{Results}

\section{Patients}

Of the 744 patients who were randomized, $676(90.9 \%)$ patients completed the study (QVA149 number $[\mathrm{n}]=343$; SFC $\mathrm{n}=333$; Figure 2). A similar percentage of patients completed both treatment arms (92.2\% QVA149 and 89.5\% SFC) with adverse events (AEs) being the common reason for discontinuation in both groups (3.0\% QVA149 and 4.8\% SFC).

\section{Patient demographics and baseline characteristics}

Patient demographics were comparable between treatment arms (Table 1). Most patients were male (91.7\% in QVA149 and $89.7 \%$ in SFC) and from the People's Republic of China $(80 \%)$. The majority of patients $(98.6 \%)$ in both treatment arms had moderate or severe COPD, as defined by the GOLD 2010 strategy. ${ }^{21}$ Only $16.4 \%$ of QVA149 and $25.2 \%$ of SFC patients had a history of exacerbation in the past year. The mean postbronchodilator \% predicted $\mathrm{FEV}_{1}$ was approximately $52 \%$ in both groups. When mMRC scores and lung function were assessed, as per the GOLD 2014 guidelines, $53 \%$ were classified as GOLD B and 47\% classified as GOLD D. ${ }^{23}$ Prior to study enrollment, $74 \%$ of patients were using COPD-related medications and this was well balanced between both treatment arms (QVA149 72.0\%; SFC 75.9\%). ICS use at baseline was similar between the treatment arms (QVA149 55.4\%; SFC 54.2\%).

\section{Spirometry}

At week 26, QVA149 was deemed to be noninferior to SFC by meeting the predefined noninferiority margin of $-60 \mathrm{~mL}$ in trough $\mathrm{FEV}_{1}$ (treatment difference $[\Delta]=72 \mathrm{~mL} ; 95 \% \mathrm{CI}$ : $40,104)$ for the per protocol set. QVA149 treatment demonstrated statistically significant superiority to SFC for trough $\mathrm{FEV}_{1}(\Delta=75 \mathrm{~mL}, 95 \% \mathrm{CI}: 44,107 ; P<0.001$; Figure 3 and Table 2) for the FAS. This significant improvement in trough $\mathrm{FEV}_{1}$ with QVA149 treatment compared with SFC was also observed at day $1(\Delta=43 \mathrm{~mL}, P<0.001)$ and had reached a steady state by week $12(\Delta=78 \mathrm{~mL} ; P<0.001$; Figure 3

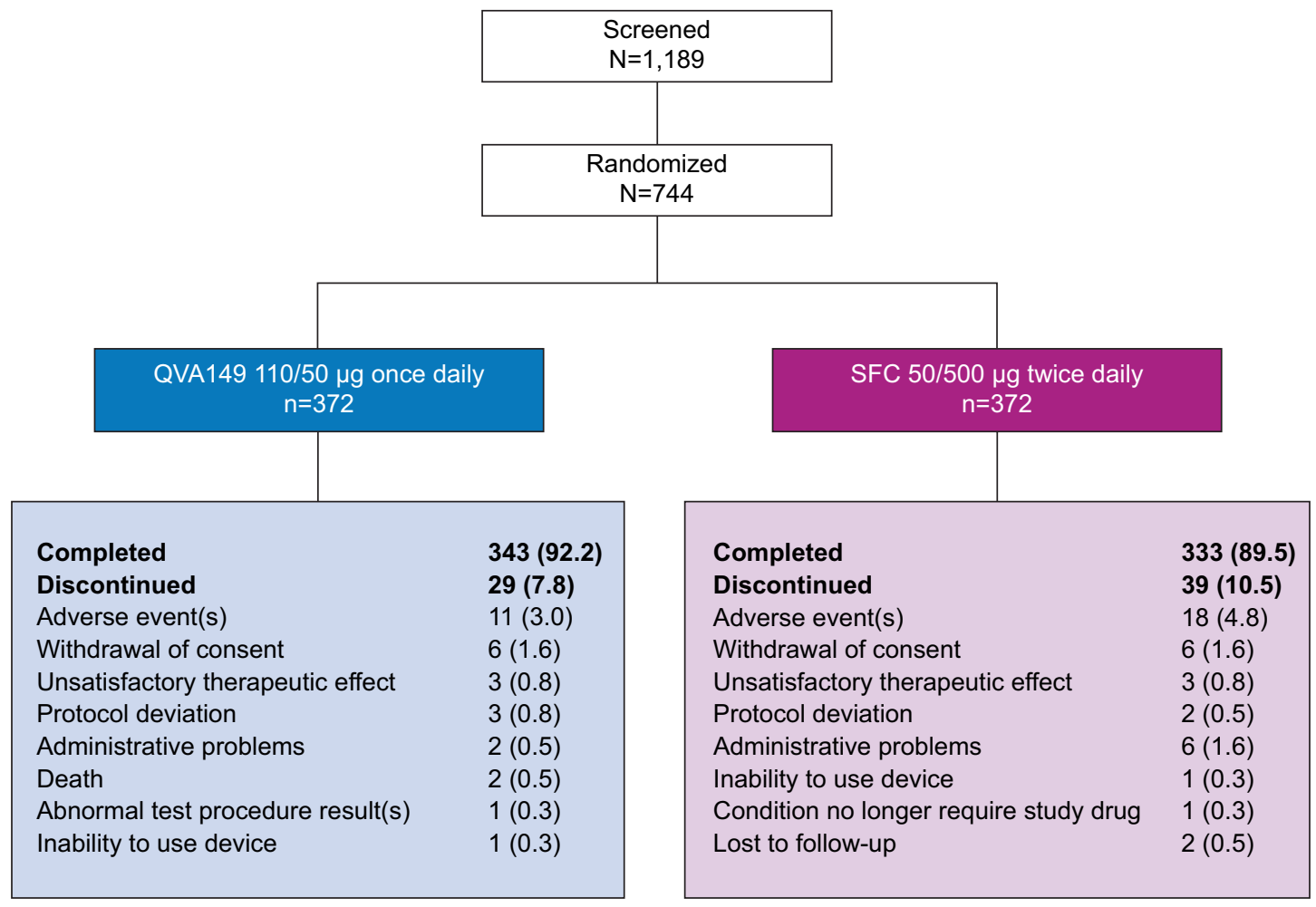

Figure 2 LANTERN trial profile.

Note: Data are shown as $\mathrm{n}(\%)$

Abbreviation: SFC, salmeterol/fluticasone. 
Table I Demographics and baseline patient characteristics

\begin{tabular}{|c|c|c|}
\hline Patient characteristics & $\begin{array}{l}\text { QVAI } 49 \\
\text { I I } 0 / 50 \mu \mathrm{g} \text { od } \\
\mathrm{n}=372\end{array}$ & $\begin{array}{l}\text { SFC } \\
50 / 500 \mu \mathrm{g} \text { bid } \\
\mathrm{n}=369\end{array}$ \\
\hline Age, years & $64.8(7.8)$ & $65.3(7.9)$ \\
\hline Sex, male, n (\%) & $34 \mid(91.7)$ & $331(89.7)$ \\
\hline \multicolumn{3}{|l|}{ Race, n (\%) } \\
\hline Caucasian & $55(14.8)$ & $58(I 5.7)$ \\
\hline Asian & $314(84.4)$ & $309(83.7)$ \\
\hline Other & $3(0.8)$ & $2(0.5)$ \\
\hline Duration of COPD, years & $5.2(4.9)$ & $5.1(4.7)$ \\
\hline \multicolumn{3}{|l|}{ COPD severity, n (\%) } \\
\hline Mild & $2(0.5)$ & $\mathrm{I}(0.3)$ \\
\hline Moderate & $192(51.6)$ & $195(52.8)$ \\
\hline Severe & $175(47.0)$ & $169(45.8)$ \\
\hline \multicolumn{3}{|l|}{ GOLD 2014 groups } \\
\hline GOLD B & $193(51.9)$ & $196(53.1)$ \\
\hline GOLD D & $176(47.3)$ & $169(45.8)$ \\
\hline $\begin{array}{l}\text { Patients with prior COPD-related } \\
\text { medication, } \mathrm{n}(\%)\end{array}$ & $268(72.0)$ & $280(75.9)$ \\
\hline ICS users at baseline, $\mathrm{n}(\%)$ & $206(55.4)$ & $200(54.2)$ \\
\hline Current smokers, n (\%) & $96(25.8)$ & $96(26.0)$ \\
\hline \multicolumn{3}{|l|}{ COPD exacerbation history, $\mathrm{n}(\%)$} \\
\hline 0 & $311(83.6)$ & $276(74.8)$ \\
\hline I & $60(16.1)$ & $93(25.2)$ \\
\hline$\geq 2$ & $\mathrm{I}(0.3)$ & 0 \\
\hline Postbronchodilator FEV, $\mathrm{L}$ & $1.336(0.392)$ & I.34I (0.4I8) \\
\hline Postbronchodilator $\mathrm{FEV}$, \% predicted & $51.6(12.8)$ & $52.0(12.9)$ \\
\hline Postbronchodilator FEV, reversibility, \% & $25.3(16.9)$ & $22.8(16.7)$ \\
\hline Postbronchodilator $\mathrm{FEV}_{1} / \mathrm{FVC}, \%$ & $42.7(9.9)$ & $43.0(10.0)$ \\
\hline CAT score & $13.7(5.94)$ & $13.8(6.78)$ \\
\hline \multicolumn{3}{|l|}{ CAT score category } \\
\hline $0-10$ (mild) & $119(32.0)$ & $137(37.1)$ \\
\hline II-20 (moderate) & $198(53.2)$ & $155(42.0)$ \\
\hline $21-30$ (severe) & $52(14.0)$ & $70(19.0)$ \\
\hline $3 \mathrm{I}-40$ (very severe) & 0 & $2(0.5)$ \\
\hline Missing & $3(0.8)$ & $5(1.4)$ \\
\hline BDI focal score & $6.3(1.79)$ & $6.4(1.89)$ \\
\hline SGRQ total score & $39.25(15.40)$ & 38.81 (15.49) \\
\hline \multicolumn{3}{|l|}{ mMRC grade } \\
\hline 2 & $331(89.0)$ & $325(88.1)$ \\
\hline 3 & $35(9.4)$ & $40(10.8)$ \\
\hline 4 & $6(1.6)$ & $4(1.1)$ \\
\hline
\end{tabular}

Notes: Data are the mean \pm standard deviation, unless otherwise stated; ${ }^{\mathrm{a}} \mathrm{COPD}$ severity is based on GOLD 2010 criteria.

Abbreviations: od, once daily; bid, twice daily; SFC, salmeterol/fluticasone; GOLD, Global initiative for chronic Obstructive Lung Disease; ICS, inhaled corticosteroid; FEV , forced expiratory volume in I second; FVC, forced vital capacity; CAT, COPD assessment test; BDI, baseline dyspnea index; SGRQ, St George's Respiratory Questionnaire; mMRC, modified Medical Research Council.

and Table 2). QVA149 demonstrated statistically significant improvements in $\mathrm{FEV}_{1} \mathrm{AUC}_{0-4 \mathrm{~h}}$ at day 1 and week 26 when compared with SFC $(\Delta=65 \mathrm{~mL}$ and $\Delta=122 \mathrm{~mL}$, respectively; all $P<0.001$; Table 2). The peak $\mathrm{FEV}_{1}$ was significantly higher at day 1 and week 26 in the QVA149 treatment arm compared with SFC (all $P<0.001$; Table 2). Trough FVC was significantly higher for QVA149 than for
SFC $(P<0.001$; Table 2$)$. Similarly, statistically significant improvements in peak FVC (taken over the first 4 hours) was observed in QVA149 when compared with SFC at day 1 and week 26 (all $P<0.001$; Table 2). A higher percentage of patients in the QVA149 group achieved an improvement of $\geq 100 \mathrm{~mL}$ (QVA149 60.6\%; SFC $44.2 \%$ ) or $\geq 200 \mathrm{~mL}$ (QVA149 43.7\%; SFC 24.7\%) in trough FEV from baseline to week 26 when compared with SFC (Table S3). The primary endpoint (trough $\mathrm{FEV}_{1}$ at week 26) was also analyzed by various subgroups including current smoking status, ICS use at baseline, severity of COPD, age, and COPD exacerbation history with all comparisons favoring QVA149 over SFC (Figure 4).

\section{Dyspnea, health status, rescue medication, and patient symptoms}

Patients treated with QVA149 and SFC had improvements in their TDI focal score at weeks 12 and 26 when compared to their respective baselines, which were substantially greater than the minimally clinically important difference (MCID) of one unit, although no statistical difference was observed between the two groups at weeks 12 and $26(P=0.15$ and $P=0.44$, respectively; Table 2$)$. There was a similar improvement in the SGRQ total score between patients receiving QVA149 and SFC at weeks 12 and 26 (Table 2). The mean change from baseline in SGRQ was also greater than the accepted MCID of four units in both treatment arms. Analysis of the patients' symptoms, the use of rescue medication, and the total CAT scores after 26 weeks were also comparable between QVA149 and SFC (Table 2). Patient-recorded symptoms were also similar between the two groups (Table S4).

\section{Moderate or severe exacerbations}

In the overall patient population, the annualized rate of moderate or severe COPD exacerbations was significantly lower in the QVA149 treatment arm compared with SFC treatment arm $(P=0.048)$, indicating a risk reduction of $31 \%$ (Table 3). QVA149 also significantly prolonged the time to first moderate or severe exacerbation and reduced the hazard of having such exacerbations by $35 \%$ when compared with $\mathrm{SFC}$ treatment ( $P=0.028$; Figure 5 ).

Due to the observed different percentages of patients with a history of exacerbation at baseline in the treatment groups ( $16.4 \%$ of QVA149 and $25.2 \%$ of SFC), post hoc analyses were performed on subgroups of patients with or without a baseline history of exacerbation. The rate of moderate or severe COPD exacerbations was analyzed in these subgroups 


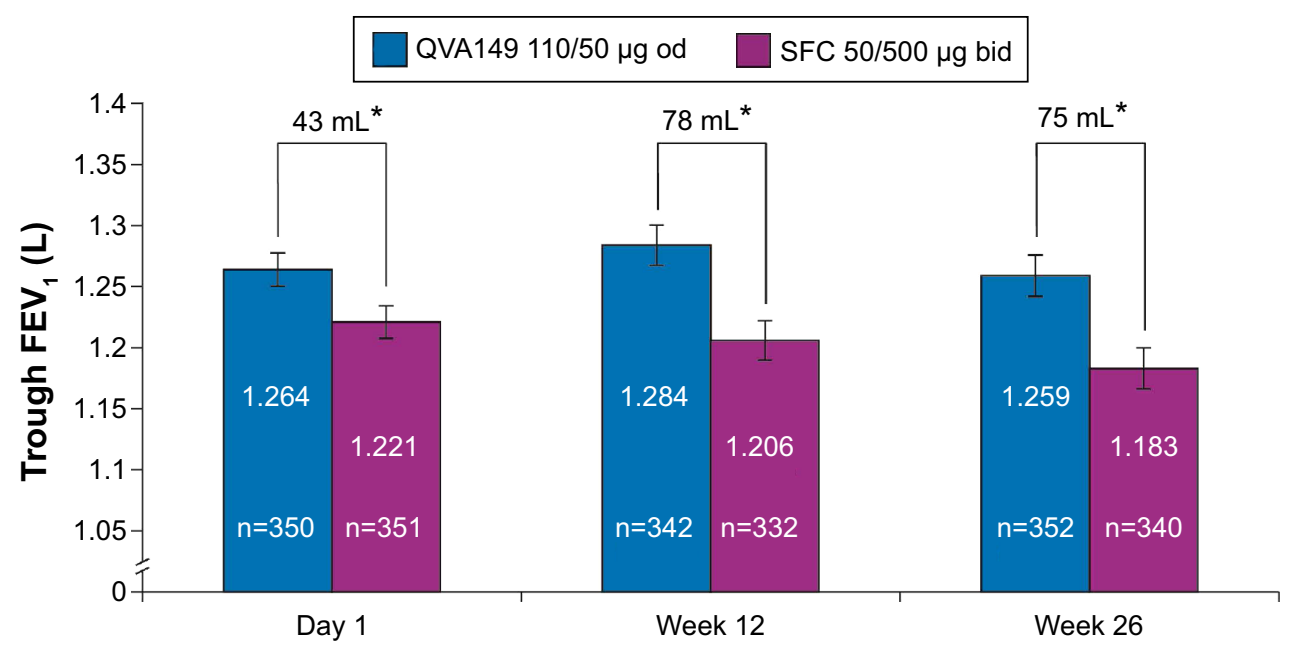

Figure 3 Trough FEV, on day I and at weeks 12 and 26 (full analysis set).

Notes: Data are least square means \pm standard error; $* p<0.00$ I.

Abbreviations: bid, twice daily; FEV , forced expiratory volume in I second; od, once daily; SFC, salmeterol/fluticasone.

of patients with the same negative binomial model used for the overall population, except without the baseline COPD exacerbation history term in the model. In patients with a history of moderate or severe exacerbations at baseline, the annualized rate of moderate or severe COPD exacerbations was $40 \%$ lower in the QVA149 treatment arm compared with the SFC treatment arm (rate ratio: 0.60 ; 95\% CI: 0.33, 1.08; Table 4). In only those patients without a history of moderate or severe exacerbations at baseline, the annualized rate of moderate or severe COPD exacerbations was 34\% lower in the QVA149 treatment arm compared with SFC treatment arm (rate ratio: 0.76 ; $95 \%$ CI: 0.46, 1.24; Table 4).

Although the differences in these subgroups were not statistically significant (the subgroups were not powered for hypothesis testing), the results for both subgroups were consistent in that fewer QVA149 patients experienced exacerbations compared to SFC patients. Further evaluations of exacerbations can be found in Table S5 and Figure S1.

\section{Safety}

Overall, AEs were lower in the patients treated with QVA149 compared with SFC (Table 5). More patients in the SFC treatment arm reported a COPD-related AE when compared with QVA149 (26.3\% and $20.2 \%$, respectively). In the LANTERN study, fewer cases of pneumonia were reported in the QVA149 group ( $\mathrm{n}=3$ [0.8\%]) compared with the SFCtreated patients $(n=10[2.7 \%])$. Similarly, there were fewer upper respiratory tract infections reported in the QVA149 treatment arm $(\mathrm{n}=13$ [3.5\%]) compared with the SFC arm $(n=26[7.0 \%])$. AEs leading to discontinuation were more frequent with SFC compared with QVA149. COPD worsening was the most common $\mathrm{AE}$ leading to discontinuation in both treatment arms (QVA149, 0.8\%; SFC, 1.9\%) (Table 5). The total number of AEs leading to hospitalization was almost double in the SFC group ( $\mathrm{n}=31$ [8.4\%]) when compared with the QVA149 group ( $\mathrm{n}=16$ [4.3\%]). Similarly, the two leading causes of such hospitalization (COPD exacerbation and pneumonia) were more prominent in the SFC group $(n=16[4.3 \%]$ and $n=4[1.1 \%]$, respectively) when compared with QVA149 $(\mathrm{n}=6$ [1.6\%] and $\mathrm{n}=2$ [0.5\%], respectively; Figure S2).

The incidence of serious AEs was lower in QVA149treated patients when compared to the SFC group. COPD was the major cause of serious AEs and was higher in the SFC treatment arm when compared to the QVA149 arm (Table 5). The incidence of major adverse cardiovascular events was comparable between the treatment groups (QVA149, 0.8\%; SFC, $0.3 \%$ ). As would be expected to occur in an elderly patient population with comorbidities, two deaths were reported within the QVA149 treatment arm.

\section{Discussion}

In this study, QVA149 once daily was compared with the LABA/ICS fixed-dose combination, SFC, administered twice daily in patients with moderate-to-severe COPD. The primary endpoint of this study was achieved, whereby QVA149 demonstrated noninferiority by trough $\mathrm{FEV}_{1}$ when compared with SFC at week 26, and it also demonstrated superiority on this endpoint. In this study, trough $\mathrm{FEV}_{1}$ was considered as a primary endpoint to assess the bronchodilator effect. As SFC was administered twice daily, it was important to determine 


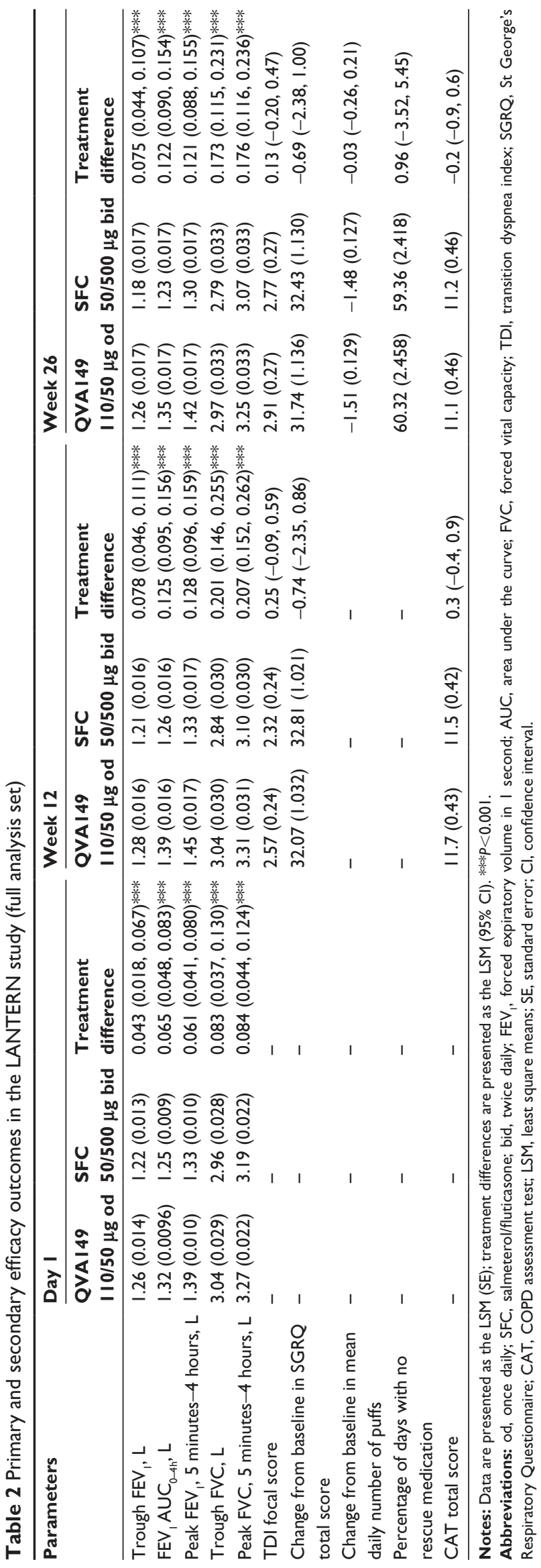

the bronchodilator effect after twice daily administration - ie, at trough $\mathrm{FEV}_{1}$. Furthermore, improvement in trough $\mathrm{FEV}_{1}$ in all subgroups based on age, smoking history, COPD severity, ICS use at baseline, and exacerbations in the previous year was generally consistent with the overall study population. Also, a statistically superior improvement in the key secondary endpoint, $\mathrm{FEV}_{1} \mathrm{AUC}_{0-4 \mathrm{~h}}$ and statistically significant improvements in other lung functions (trough FVC, peak $\mathrm{FEV}_{1}$, and peak FVC) were observed with QVA149 treatment compared with SFC treatment. Thus, the LANTERN study provides further evidence for the superiority of LABA/ LAMA combination therapy over LABA/ICS for improvement in lung function, as has been previously demonstrated by other studies. ${ }^{19,24}$

The current GOLD strategy document recommends that the use of ICS is reserved for patients with severe or very severe airflow limitation and/or $\geq 2$ exacerbations per year (GOLD groups C and D). ${ }^{5}$ This recommendation is based on data from earlier studies, which indicated that patients with a history of frequent exacerbations were more likely to benefit from ICS treatment. ${ }^{6-8}$ Although GOLD recommends ICS/LABA as a first choice for groups $\mathrm{C}$ and $\mathrm{D}$, there is evidence that the majority of these patients are in these GOLD categories due to low lung function and symptoms (mMRC or CAT) rather than frequent exacerbations. ${ }^{25}$ The benefit of ICS-based therapy in these patients has not been adequately tested. Despite these recommendations, ICS is often misused by being prescribed earlier in the course of the disease to more moderate COPD patients, ${ }^{9-11}$ although a number of side-effects are associated with ICS. ${ }^{26-30}$ When COPD severity was classified according to $\mathrm{FEV}_{1},{ }^{21} 47 \%$ and $45.8 \%$ of patients in the QVA149 and SFC treatment arms, respectively, were classified as having severe COPD. While almost $50 \%$ of the patients met the GOLD criteria for group D, most of these patients were in GOLD D due to having an $\mathrm{FEV}_{1}<50 \%$ predicted and not due to frequent exacerbations, and QVA149 treatment was superior in this group. For patients with $\leq 1$ exacerbation that are in GOLD D because of airflow limitation, results from LANTERN suggest that these patients should be receiving a LABA/LAMA instead of LABA/ICS.

An important outcome from LANTERN is the effect of QVA149 treatment on COPD moderate or severe exacerbations, when compared with LABA/ICS. Central to COPD management is the prevention of exacerbations. ${ }^{31}$ Previous studies have demonstrated the ability of $\mathrm{LABA}^{32}$ and $\mathrm{LAMA}^{33}$ monotherapies and LABA/ICS ${ }^{34}$ to reduce the exacerbation rates in COPD when compared to placebo. 


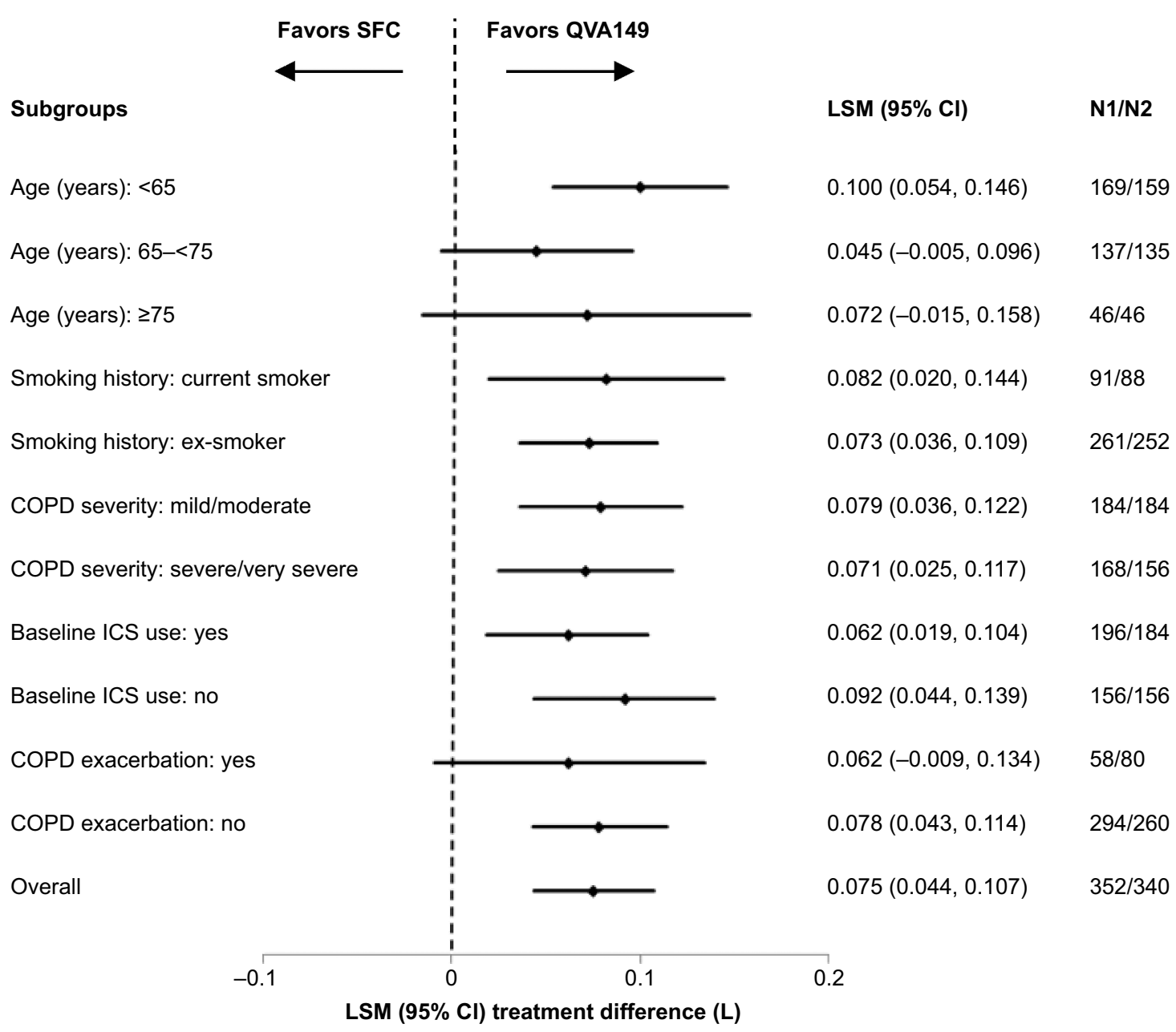

Figure 4 Forest plot of the treatment difference of trough FEV $(\mathrm{L})$ at week 26 by smoking history, baseline ICS use, COPD severity, and age for QVAI49 and SFC after 26 weeks of treatment (LOCF).

Abbreviations: SFC, salmeterol/fluticasone; LSM, least square means; Cl, confidence interval; NI, number of patients analyzed in the QVAI49 group; N2, number of patients analyzed in the salmeterol/fluticasone group; ICS, inhaled corticosteroid; FEV , forced expiratory volume in I second; LOCF, last observation carried forward.

Table 3 Summary and analysis of COPD exacerbations over 26 weeks by treatment group (full analysis set)

\begin{tabular}{|c|c|c|}
\hline \multirow[t]{2}{*}{ Parameters } & \multicolumn{2}{|c|}{$\begin{array}{l}\text { Moderate or severe COPD } \\
\text { exacerbations }\end{array}$} \\
\hline & $\begin{array}{l}\text { QVAI } 49 \\
\text { I I } 0 / 50 \mu \mathrm{g} \text { od } \\
(\mathrm{n}=372)\end{array}$ & $\begin{array}{l}\text { SFC } 50 / 500 \mu \mathrm{g} \\
\text { bid }(n=369)\end{array}$ \\
\hline \multicolumn{3}{|l|}{ Exacerbations per patient, n (\%) } \\
\hline 0 & $328(88.2)$ & $30 I(8 I .6)$ \\
\hline 1 & $35(9.4)$ & $55(14.9)$ \\
\hline 2 & $9(2.4)$ & $13(3.5)$ \\
\hline 3 & 0 & 0 \\
\hline$\geq 4$ & 0 & 0 \\
\hline Total number of exacerbations & 53 & 81 \\
\hline Total number of treatment years & 179.2 & 174.9 \\
\hline Rate of exacerbations per year & 0.30 & 0.46 \\
\hline \multicolumn{3}{|l|}{ Treatment comparison versus SFC } \\
\hline Ratio of rate $(95 \% \mathrm{Cl})$ & $0.69(0.48,1.00)^{*}$ & \\
\hline
\end{tabular}

Note: $* p<0.05$.

Abbreviations: SFC, salmeterol/fluticasone; $\mathrm{Cl}$, confidence interval, od, once daily; bid, twice daily.
In the INSPIRE (Investigating New Standards for Prophylaxis In Reducing Exacerbations) study, ${ }^{35}$ LAMA monotherapy was comparable to LABA/ICS in terms of the rate of exacerbations experienced by COPD patients. In the LANTERN study, patients receiving QVA149 had a significant reduction in moderate or severe exacerbations when compared to those receiving SFC.

LANTERN confirms the results of the ILLUMINATE study, ${ }^{18}$ while also building upon this data. A post hoc analysis of ILLUMINATE demonstrated that QVA149 delayed the time to first exacerbation when compared with SFC in a population in which $19.8 \%$ of patients had severe COPD. ${ }^{18,19}$ In the LANTERN study, the hazard ratio for the time to first moderate or severe exacerbation was also significantly delayed in a study population in which almost half the cases were classified as severe (GOLD D) and had a lower mean postbronchodilator $\mathrm{FEV}_{1}$ at baseline when compared to the ILLUMINATE population. Significant improvements in lung 


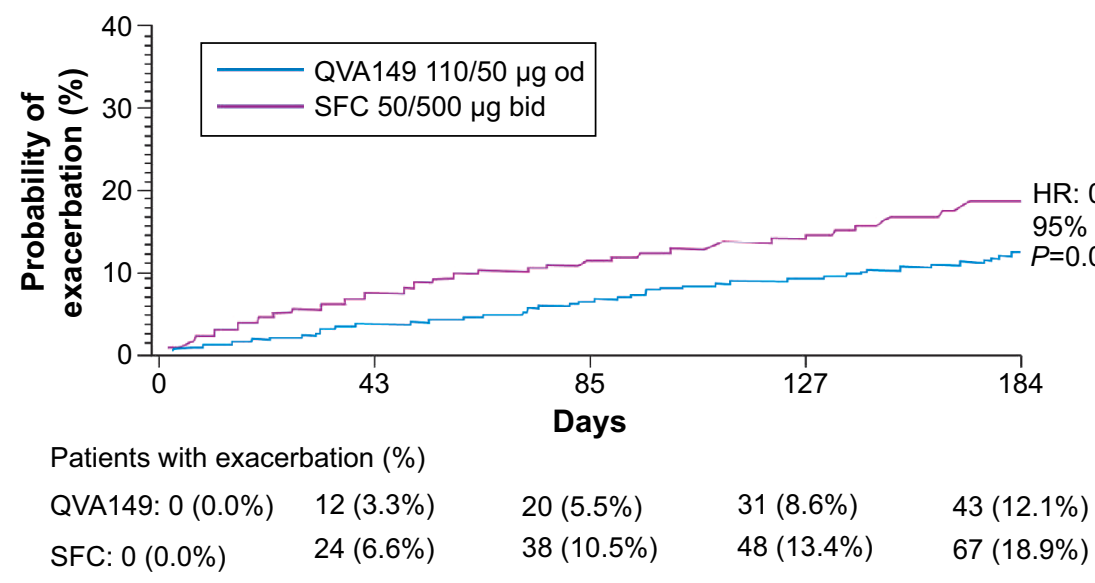

Figure 5 Kaplan-Meier plots of the time to first moderate or severe COPD exacerbation over 26 weeks of treatment (full analysis set). Abbreviations: SFC, salmeterol/fluticasone; HR, hazard ratio; $\mathrm{Cl}$, confidence interval; od, once daily; bid, twice daily.

function with QVA149 might be the reason for the reduction in the risk of exacerbations. It has been demonstrated in a Swedish study that QVA149 is cost effective when compared with SFC, whereby the total estimated costs associated with the drug, maintenance, exacerbation, pneumonia, and indirect costs were lower and resulted in better outcomes with QVA149 when compared with SFC. ${ }^{36}$

A further study of 52 weeks' duration that is currently ongoing and builds upon previous findings ${ }^{37}$ is specifically examining the impact of QVA149 and SFC on COPD exacerbation rates in a larger patient population including patients with very severe COPD, and all of whom have had a history of moderate-severe exacerbations in the last year (FLAME study; NCT01782326). ${ }^{38}$

The management and reduction of symptoms is an essential goal of COPD treatment, because of the impact that symptoms, such as dyspnea, has on the patients' quality of life. In this study, superior bronchodilation provided by QVA149 did not translate into significant differences in symptom control versus SFC. QVA149 was comparable with SFC in improving TDI focal score, and in reducing the
SGRQ total score and the CAT total score after 26 weeks. While both QVA149 and SFC demonstrated comparable improvements in the TDI focal score and SGRQ total score from baseline after 26 weeks, the percentage of patients who achieved MCID in both of these endpoints was numerically higher with QVA149 versus SFC.

In the LANTERN study, QVA149 demonstrated a good safety profile, similar to that observed in previous studies. ${ }^{18,39}$ The overall incidence of AEs was lower in the QVA149 group compared with SFC. The use of ICS in COPD is associated with an increased risk of pneumonia, ${ }^{26,40-42}$ which was reflected in this study, where SFC showed a threefold higher incidence of pneumonia compared with QVA149. There was also a higher number of AEs leading to hospitalization observed in the SFC group compared to the QVA149 group. The safety profile of QVA149 in this study was consistent with earlier studies, which demonstrated that QVA149 was well tolerated ${ }^{39}$ and the overall safety profile is comparable to placebo and its monocomponents. ${ }^{43,44}$

There are limitations to this study that have to be acknowledged. Firstly, with regards to the study population, a full

Table 4 Annualized rate of moderate or severe COPD exacerbation by baseline COPD exacerbation history

\begin{tabular}{|c|c|c|c|c|c|}
\hline Treatment & $\begin{array}{l}\text { Annualized } \\
\text { rate }(95 \% \mathrm{Cl})\end{array}$ & Comparison & Rate ratio & $95 \% \mathrm{Cl}$ & $P$-value \\
\hline \multicolumn{6}{|c|}{ With COPD exacerbation history at baseline } \\
\hline QVAI49 II0/50 $\mu$ g od $(n=6 I)$ & $0.49(0.29,0.82)$ & QVAI49/SFC & 0.60 & $(0.33,1.08)$ & 0.086 \\
\hline SFC $50 / 500 \mu g$ bid $(n=93)$ & $0.81(0.56,1.19)$ & & & & \\
\hline \multicolumn{6}{|c|}{ Without COPD exacerbation history at baseline } \\
\hline QVAI49 II0/50 $\mu \mathrm{g}$ od $(\mathrm{n}=3$ II) & $0.23(0.16,0.33)$ & QVAI49/SFC & 0.76 & $(0.46,1.24)$ & 0.266 \\
\hline SFC $50 / 500 \mu \mathrm{g}$ bid $(\mathrm{n}=276)$ & $0.30(0.2 \mathrm{I}, 0.43)$ & & & & \\
\hline
\end{tabular}

Notes: Rate ratio, its $95 \% \mathrm{Cl}$, and $P$-value are from a negative binomial regression model: Log (exacerbation rate) $=$ treatment + baseline ICS use (yes/no) + baseline total symptom score $+\mathrm{FEV}$, reversibility components. Log (length of time in the study) is included in the model as an offset term.

Abbreviations: $\mathrm{Cl}$, confidence interval; SFC, salmeterol/fluticasone; ICS, inhaled corticosteroid; od, once daily; bid, twice daily. 
Table 5 Number (\%) of AEs, SAEs, and deaths (safety set)

\begin{tabular}{|c|c|c|}
\hline Parameters & $\begin{array}{l}\text { QVAI } 49 \\
\text { II } 0 / 50 \mu \mathrm{g} \text { od } \\
\mathbf{N}=372\end{array}$ & $\begin{array}{l}\text { SFC } \\
50 / 500 \mu g \\
\text { bid } N=369\end{array}$ \\
\hline Any $A E$ & $149(40.1)$ & $175(47.4)$ \\
\hline \multicolumn{3}{|l|}{ Any $A E s$ in $\geq 1.5 \%$ of any group } \\
\hline COPD worsening ${ }^{a}$ & $75(20.2)$ & $97(26.3)$ \\
\hline Nasopharyngitis & $30(8.1)$ & $45(12.2)$ \\
\hline Upper respiratory tract infection & $13(3.5)$ & $26(7.0)$ \\
\hline Bronchitis & $7(1.9)$ & $4(1.1)$ \\
\hline Pneumonia & $3(0.8)$ & $10(2.7)$ \\
\hline Dyspnea & $2(0.5)$ & $6(1.6)$ \\
\hline Oropharyngeal pain & $2(0.5)$ & $6(1.6)$ \\
\hline AEs leading to discontinuation & $12(3.2)$ & $17(4.6)$ \\
\hline COPD worsening & $3(0.8)$ & $7(1.9)$ \\
\hline Any SAE & $20(5.4)$ & $35(9.5)$ \\
\hline COPD & $6(1.6)$ & $17(4.6)$ \\
\hline SAEs leading to discontinuation & $9(2.4)$ & $11(3.0)$ \\
\hline Non-SAE(s) leading to discontinuation & $3(0.8)$ & $7(1.9)$ \\
\hline Deaths & $2(0.5)$ & 0 \\
\hline
\end{tabular}

Notes: ancluding COPD exacerbations. Data are shown as $n$ (\%).

Abbreviations: AE, adverse event; SAE, serious adverse event; SFC, salmeterol/ fluticasone; od, once daily; bid, twice daily.

range of COPD severities was not included. Future studies will include very severe COPD patients and evaluate the impact of QVA149 on this population. Another limitation is that the patient-reported outcomes (PROs) did not parallel the improvement in lung function observed with QVA149 when compared with SFC. While some of the data were numerically better with QVA149 treatment, statistical significance was not achieved. This confirms the data thus far available, as discussed in the recent review by Ridolo et al. ${ }^{45}$ This could be due to how patients perceive their COPD symptoms impacting PROs. ${ }^{46}$ It is also unclear if PROs are sensitive enough to pick up differences between highly active therapies; hence, in the LANTERN study, the superiority of QVA149 over SFC in lung function data was not reflected in terms of significant differences in the PROs. Another potential limitation of this study is the relatively short duration (26 weeks), over which exacerbations were measured and compared with prior studies that investigated this endpoint. Importantly, there was a higher proportion of patients randomized to SFC who had a prior history of moderate or severe exacerbations at baseline, but that was a random phenomenon. However, this imbalance was accounted for in the prespecified statistical model. The results were further supported by the post hoc subgroup analyses (those with and without a history of exacerbations at baseline). In both subgroups of patients, a reduction in the rate of moderate or severe exacerbations with QVA149 compared with SFC was observed. The absence of inconsistent results suggests an interesting observation, which may be clinically meaningful.

\section{Conclusion}

In conclusion, the LANTERN study confirms the potential of QVA149 as a treatment option for symptomatic COPD patients with a history of $\leq 1$ exacerbation in the previous year, offering additional benefits over LABA/ICS combinations. This study builds upon the good safety profile previously reported for QVA149, ${ }^{44}$ and further supports QVA149 as a treatment option that can result in significantly reducing moderate or severe COPD exacerbations. Thus, LANTERN contributes to the understanding of the optimal therapy for patients at risk of exacerbation.

\section{Acknowledgments}

Details of, and a complete list of, the LANTERN study Investigators may be found in the online Supplementary materials. This study is registered at ClinicalTrials.gov with clinical trial NLM identifier number: NCT01709903. This study was sponsored by Novartis Pharma AG. The authors would like to thank patients and staff at the participating centers. The authors also thank David Bergin and Santanu Sannigrahi (professional medical writers; Novartis) for assistance in the preparation of this paper. Writing support was funded by the study sponsor. This study was published as an abstract and presented at the European Respiratory Society International Congress 2014, Munich, Germany, 6-10 September 2014.

\section{Author contributions}

N Zhong, C Wang, X Zhou, and N Zhang coordinated the investigator centers, collected clinical data, and contributed to the writing of the manuscript. M Humphries centrally coordinated, educated, and monitored the centers. M Humphries, L Wang, C Thach, F Patalano, and D Banerji helped with the study design, oversaw statistical analyses, and helped to write the manuscript.

\section{Disclosure}

This study was sponsored by Novartis Pharma AG. M Humphries, L Wang, C Thach, F Patalano, and D Banerji are employees of the study sponsor, Novartis. The authors report no other conflicts of interest in this work.

\section{References}

1. Global Initiative for Chronic Obstructive Lung Disease (GOLD). Global Strategy for the Diagnosis, Management, and Prevention of Chronic Obstructive Pulmonary Disease: Updated 2015. Seattle, WA: Global Initiative for Chronic Obstructive Lung Disease (GOLD); 2015. Available from: http://www.goldcopd.org/uploads/users/files/ GOLD_Report_2015_Feb18.pdf. Accessed March 14, 2015.

2. Blasi F, Cesana G, Conti S, et al. The clinical and economic impact of exacerbations of chronic obstructive pulmonary disease: a cohort of hospitalized patients. PLoS One. 2014;9(6):e101228. 
3. Miravitlles M, Sicras A, Crespo C, et al. Costs of chronic obstructive pulmonary disease in relation to compliance with guidelines: a study in the primary care setting. Ther Adv Respir Dis. 2013;7(3):139-150.

4. Rutten-van Mölken MP, Goossens LM. Cost effectiveness of pharmacological maintenance treatment for chronic obstructive pulmonary disease: a review of the evidence and methodological issues. Pharmacoeconomics. 2012;30(4):271-302.

5. Calverley P, Pauwels R, Vestbo J, et al; TRial of Inhaled STeroids ANd long-acting beta2 agonists study group. Combined salmeterol and fluticasone in the treatment of chronic obstructive pulmonary disease: a randomised controlled trial. Lancet. 2003;361(9356):449-456.

6. Jones PW, Willits LR, Burge PS, Calverley PM; Inhaled Steroids in Obstructive Lung Disease in Europe study investigators. Disease severity and the effect of fluticasone propionate on chronic obstructive pulmonary disease exacerbations. Eur Respir J. 2003;21(1):68-73.

7. Mahler DA, Wire P, Horstman D, et al. Effectiveness of fluticasone propionate and salmeterol combination delivered via the Diskus device in the treatment of chronic obstructive pulmonary disease. Am J Respir Crit Care Med. 2002;166(8):1084-1091.

8. Jochmann A, Neubauer F, Miedinger D, Schafroth S, Tamm M, Leuppi JD. General practitioner's adherence to the COPD GOLD guidelines: baseline data of the Swiss COPD Cohort Study. Swiss Med Wkly. Epub 2010 Apr 21.

9. Suissa S, Barnes PJ. Inhaled corticosteroids in COPD: the case against. Eur Respir J. 2009;34(1):13-16.

10. Cazzola M, Molimard M. The scientific rationale for combining longacting beta2-agonists and muscarinic antagonists in COPD. Pulm Pharmacol Ther. 2010;23(4):257-267.

11. Bateman ED, Ferguson GT, Barnes N, et al. Dual bronchodilation with QVA149 versus single bronchodilator therapy: the SHINE study. Eur Respir J. 2013;42(6):1484-1494.

12. Tashkin DP, Donohue JF, Mahler DA, et al. Effects of arformoterol twice daily, tiotropium once daily, and their combination in patients with COPD. Respir Med. 2009;103(4):516-524.

13. van Noord JA, Aumann JL, Janssens E, et al. Comparison of tiotropium once daily, formoterol twice daily and both combined once daily in patients with COPD. Eur Respir J. 2005;26(2):214-222.

14. van Noord JA, Aumann JL, Janssens E, et al. Combining tiotropium and salmeterol in COPD: Effects on airflow obstruction and symptoms Respir Med. 2010;104(7):995-1004.

15. van Noord JA, Aumann JL, Janssens E, et al. Effects of tiotropium with and without formoterol on airflow obstruction and resting hyperinflation in patients with COPD. Chest. 2006;129(3):509-517.

16. van Noord JA, Buhl R, Laforce C, et al. QVA149 demonstrates superior bronchodilation compared with indacaterol or placebo in patients with chronic obstructive pulmonary disease. Thorax. 2010; 65(12):1086-1091.

17. Vogelmeier C, Kardos P, Harari S, Gans SJ, Stenglein S, Thirlwell J. Formoterol mono- and combination therapy with tiotropium in patients with COPD: a 6-month study. Respir Med. 2008;102(11):1511-1520.

18. Vogelmeier CF, Bateman ED, Pallante J, et al. Efficacy and safety of once-daily QVA149 compared with twice-daily salmeterol-fluticasone in patients with chronic obstructive pulmonary disease (ILLUMINATE): a randomised, double-blind, parallel group study. Lancet Respir Med. 2013;1(1):51-60.

19. Banerji D, Fedele MJ, Chen H, Kim HJ. Dual bronchodilation with QVA149 reduces COPD exacerbations: results from the IGNITE program (OS36: COPD 3). Respirol. 2013;18(S4):69-70.

20. Zhong N, Wang C, Zhou X, et al. Efficacy and safety of once-daily QVA149 compared with twice-daily salmeterol/fluticasone combination (SFC) in patients with COPD: the LANTERN study [abstract]. Eur Respir J. 2014;44 Suppl 58:P2815.

21. Global Initiative for Chronic Obstructive Lung Disease (GOLD). Global Strategy for the Diagnosis, Management, and Prevention of Chronic Obstructive Pulmonary Disease: Updated 2010. Seattle, WA: Global Initiative for Chronic Obstructive Lung Disease (GOLD); 2010. Available from: http://www.goldcopd.org/uploads/users/files/ GOLDReport_April112011.pdf. Accessed February 12, 2014
22. Nannini LJ, Cates CJ, Lasserson TJ, Poole P. Combined corticosteroid and long-acting beta-agonist in one inhaler versus long-acting betaagonists for chronic obstructive pulmonary disease. Cochrane Database Syst Rev. 2007;(4):CD006829.

23. Global Initiative for Chronic Obstructive Lung Disease (GOLD). Global Strategy for the Diagnosis, Management, and Prevention of Chronic Obstructive Pulmonary Disease: Updated 2014. Seattle, WA: Global Initiative for Chronic Obstructive Lung Disease (GOLD); 2014. Available from: http://www.goldcopd.org/uploads/users/files/ GOLD_Report_2014_Jan23.pdf. Accessed February 15, 2014.

24. Rabe KF, Timmer W, Sagkriotis A, Viel K. Comparison of a combination of tiotropium plus formoterol to salmeterol plus fluticasone in moderate COPD. Chest. 2008;134(2):255-262.

25. Agusti A, Edwards LD, Celli B, et al; ECLIPSE Investigators. Characteristics, stability and outcomes of the 2011 GOLD COPD groups in the ECLIPSE cohort. Eur Respir J. 2013;42(3):636-646.

26. DiSantostefano RL, Sampson T, Le HV, Hinds D, Davis KJ, Bakerly ND. Risk of pneumonia with inhaled corticosteroid versus long-acting bronchodilator regimens in chronic obstructive pulmonary disease: a new-user cohort study. PLoS One. 2014;9(5):e97149.

27. Weatherall M, James K, Clay J, et al. Dose-response relationship for risk of non-vertebral fracture with inhaled corticosteroids. Clin Exp Allergy. 2008;38(9):1451-1458.

28. Suissa S, Kezouh A, Ernst P. Inhaled corticosteroids and the risks of diabetes onset and progression. Am J Med. 2010;123(11): 1001-1006.

29. Cumming RG, Mitchell P, Leeder SR. Use of inhaled corticosteroids and the risk of cataracts. $N$ Engl J Med. 1997;337(1):8-14.

30. Kim JH, Park JS, Kim KH, Jeong HC, Kim EK, Lee JH. Inhaled corticosteroid is associated with an increased risk of TB in patients with COPD. Chest. 2013;143(4):1018-1024.

31. Donaldson GC, Seemungal TA, Patel IS, Lloyd-Owen SJ, Wilkinson TM, Wedzicha JA. Longitudinal changes in the nature, severity and frequency of COPD exacerbations. Eur Respir J. 2003;22(6):931-936.

32. Mahler DA, Donohue JF, Barbee RA, et al. Efficacy of salmeterol xinafoate in the treatment of COPD. Chest. 1999;115(4):957-965.

33. Tashkin DP, Celli B, Senn S, et al; UPLIFT Study Investigators. A 4-year trial of tiotropium in chronic obstructive pulmonary disease. N Engl J Med. 2008;359(15):1543-1554.

34. Ferguson GT, Anzueto A, Fei R, Emmett A, Knobil K, Kalberg C. Effect of fluticasone propionate/salmeterol (250/50 microg) or salmeterol (50 microg) on COPD exacerbations. Respir Med. 2008; 102(8):1099-1108.

35. Wedzicha JA, Calverley PM, Seemungal TA, Hagan G, Ansari Z, Stockley RA; INSPIRE Investigators. The prevention of chronic obstructive pulmonary disease exacerbations by salmeterol/fluticasone propionate or tiotropium bromide. Am J Respir Crit Care Med. 2008; 177(1):19-26.

36. Price D, Keininger D, Costa-Scharplatz M, et al. Cost-effectiveness of the LABA/LAMA dual bronchodilator indacaterol/glycopyrronium in a Swedish healthcare setting. Respir Med. 2014;108(12): 1786-1793.

37. Wedzicha JA, Decramer M, Ficker JH, et al. Analysis of chronic obstructive pulmonary disease exacerbations with the dual bronchodilator QVA149 compared with glycopyrronium and tiotropium (SPARK): a randomised, double-blind, parallel-group study. Lancet Respir Med. 2013;1(3):199-209.

38. Wedzicha JA, Decramer M, Vestbo J, et al. A novel study design for the comparison between once-daily QVA149 and twice-daily salmeterol/ fluticasone on the reduction of COPD exacerbations: the FLAME study. Paper presented at: European Respiratory Society International Congress; September 7-11; 2013; Barcelona, Spain.

39. Dahl R, Chapman KR, Rudolf M, et al. Safety and efficacy of dual bronchodilation with QVA149 in COPD patients: the ENLIGHTEN study. Respir Med. 2013;107(10):1558-1567.

40. Calverley PM, Anderson JA, Celli B, et al; TORCH investigators. Salmeterol and fluticasone propionate and survival in chronic obstructive pulmonary disease. $N$ Engl J Med. 2007;356(8):775-789. 
41. Newton MF, O’Donnell DE, Forkert L. Response of lung volumes to inhaled salbutamol in a large population of patients with severe hyperinflation. Chest. 2002;121(4):1042-1050.

42. Singh S, Loke YK. An overview of the benefits and drawbacks of inhaled corticosteroids in chronic obstructive pulmonary disease. Int J Chron Obstruct Pulmon Dis. 2010;5:189-195.

43. Van de Maele B, Fabbri LM, Martin C, Horton R, Dolker M, Overend T. Cardiovascular safety of QVA149, a combination of Indacaterol and NVA237, in COPD patients. COPD. 2010;7(6):418-427.

44. Wedzicha JA, Dahl R, Buhl R, et al. Pooled safety analysis of the fixeddose combination of indacaterol and glycopyrronium (QVA149), its monocomponents, and tiotropium versus placebo in COPD patients. Respir Med. 2014;108(10):1498-1507.
45. Ridolo E, Montagni M, Riario-Sforza GG, Baroni M, Incorvaia C. Combination therapy with indacaterol and glycopyrronium bromide in the management of COPD: an update on the evidence for efficacy and safety. Ther Adv Respir Dis. 2015;9(2):49-55.

46. Weldam SW, Lammers JW, Heijmans MJ, Schuurmans MJ. Perceived quality of life in chronic obstructive pulmonary disease patients: a cross-sectional study in primary care on the role of illness perceptions. BMC Fam Pract. 2014;15:140.

\section{Publish your work in this journal}

The International Journal of COPD is an international, peer-reviewed journal of therapeutics and pharmacology focusing on concise rapid reporting of clinical studies and reviews in COPD. Special focus is given to the pathophysiological processes underlying the disease, intervention programs, patient focused education, and self management protocols.

\section{Dovepress}

This journal is indexed on PubMed Central, MedLine and CAS. The manuscript management system is completely online and includes a very quick and fair peer-review system, which is all easy to use. Visit $\mathrm{http}: / / \mathrm{www}$.dovepress.com/testimonials.php to read real quotes from published authors.

Submit your manuscript here: http://www.dovepress.com/international-journal-of-chronic-obstructive-pulmonary-disease-journal 